\title{
Retrograde Amnesia Associated with Fornix Lymphoma
}

\author{
Sung-Sang Yoon ${ }^{a}$ Duk L. Na ${ }^{b}$ Key-Chung Park ${ }^{a}$

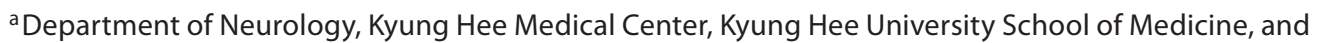 \\ ${ }^{b}$ Department of Neurology, Sungkyunkwan University School of Medicine, Samsung Medical Center, Seoul, Korea
}

\section{Dear Sir,}

Fornix is a principal tract of the Papez circuit, interconnecting the hippocampus with the anterior thalamic nuclei directly or via the mammillary body. A fornix lesion disconnects the memory circuit that runs from the temporal to the frontal lobe, causing severe anterograde amnesia [1-3]. Memory impairment in those patients was characterized by anterograde amnesia, recognition better than recall and preserved procedural memory.

To our knowledge, of 4 reported cases with a localized fornix lesion [1-4], only 1 patient was described having memory deficits for a retrograde event [4]. However, the patient retained the ability to recall past events, while only confusing their temporal order.

We evaluated a patient who suddenly developed a profound retrograde amnesia and anterograde memory impairment associated with an isolated fornix lesion.

\section{Case Report}

A 65-year-old right-handed man with 6 years of education developed abrupt memory loss and personality changes, such as apathy and indifference, 2 weeks before visiting our memory disorder clinic. He had worked as a miller for 25 years and had no history of cognitive impairment. Two weeks prior to his visit, he suddenly began to ask the same questions re- petitively, often forgetting orders from customers, and would have his employees to roast sesame too much without considering the size of the order. The family thought he seemed strange because he showed no anger when one of his employees, who had worked for him for more than 10 years, moved to a neighboring mill without telling him. His medical history was remarkable for a small infarction of the posterior limb of the right internal capsule with consequent mild left lower extremity weakness 17 years previously as well as for medication-controlled diabetes mellitus arising 3 years earlier.

On examination, the patient appeared alert and cooperative but unaware of his memory deficits. He correctly answered questions on personal information, such as his social security number, telephone number, and home address. However, he could not remember recent events, such as how he had visited the clinic and what he had eaten for lunch $1 \mathrm{~h}$ before. On MiniMental Status examination, he could not recall 3 words that he had registered only a few minutes before, scoring 20/30 due to additional problems with orientation in time and place and the last step of the Serial Seven Test.

The severity and content of cognitive decline were investigated by detailed neuropsychological tests using a standardized battery called the Seoul Neuropsychological Screening Battery [5]. The patient's scores are given in table 1 . He was able to repeat 6 digits forward but only 2 digits backward. His performances on spoken and written language were normal as were those on 10 items of praxis and on tasks for the Gerstmann syndrome. However, the patient was impaired at confrontation naming as assessed by the Korean version of the Boston Naming Test. Copying ability tested with the Rey-Osterrieth Complex Figure was intact, but immediate recall and delayed recall were impaired. Verbal memory, as assessed by the Seoul Verbal Learning Test, was also impaired, showing defective new learning and delayed recall. We could not perform the recognition section of the Seoul Verbal Learning Test because he did not even remember he had done its learning section. On the free recall concerning the presidents of Korea, he responded to only 2 of 9 (he could not recall the name of the current president). Frontal/executive functions, including controlled oral word association and Stroop Color-Word Interference Test, were severely impaired.

We suspected that the patient's remote memory was compromised, since he could not recall the previous and current presidents. Questions about significant events in his personal history were formulated to evaluate the retrograde amnesia in further detail. Whereas he remembered experiences from his twenties to forties, such as the year of his marriage and places of resi-

\section{KARGER}

Fax +41613061234

E-Mail karger@karger.ch

www.karger.com (c) 2008 S. Karger AG, Basel

0014-3022/08/0603-0155\$24.50/0

Accessible online at:

www.karger.com/ene
Key-Chung Park

Department of Neurology, Kyung Hee Medical Center

Kyung Hee University School of Medicine

1 Hoegi-dong, Dongdaemoon-ku, Seoul 130-702 (Korea)

Tel. +82 2958 8447, Fax +82 2958 8490, E-Mail kcpark67@medimail.co.kr 
Table 1. Neuropsychological test results

\begin{tabular}{|c|c|}
\hline Neuropsychological tests & Patient's scores \\
\hline \multicolumn{2}{|l|}{ Attention } \\
\hline \multicolumn{2}{|l|}{ Digit span } \\
\hline Forward & 6 (66th percentile) \\
\hline Backward & 2 (4th percentile) \\
\hline Letter cancellation & normal \\
\hline \multicolumn{2}{|l|}{ Language and related function } \\
\hline Fluency & normal \\
\hline Comprehension & normal \\
\hline Repetition & normal \\
\hline Korean version of Boston Naming Test (60) & 36 (15th percentile) \\
\hline Reading/writing & normal \\
\hline Praxis & normal \\
\hline Finger naming & normal \\
\hline Right-left orientation & normal \\
\hline Calculation & normal \\
\hline Body part identification & normal \\
\hline \multicolumn{2}{|l|}{ Visuospatial function } \\
\hline Interlocking pentagon & normal \\
\hline \multicolumn{2}{|l|}{ Copy of Rey-Osterrieth Complex } \\
\hline Figure (36) & 31 (36th percentile) \\
\hline \multicolumn{2}{|l|}{ Memory } \\
\hline \multicolumn{2}{|l|}{ Seoul Verbal Learning Test } \\
\hline 1st, $2 \mathrm{nd}, 3$ rd free recall $(12,12,12)$ & $2,3,4$ (3rd percentile) \\
\hline 20-min delayed recall (12) & 0 (<1st percentile) \\
\hline Recognition & not done \\
\hline \multicolumn{2}{|l|}{ Rey-Osterrieth Complex Figure } \\
\hline Immediate recall (36) & 0 (<1st percentile) \\
\hline 20-min delayed recall (36) & 0 (<1st percentile $)$ \\
\hline Recognition & not done \\
\hline \multicolumn{2}{|l|}{ Frontal executive function } \\
\hline Alternating square and triangle & normal \\
\hline Luria loop & normal \\
\hline \multicolumn{2}{|l|}{ Controlled Oral Word Association Test } \\
\hline Animal & 7 (<1st percentile) \\
\hline Supermarket & $2(<1$ st percentile $)$ \\
\hline Letter $\left.\left({ }^{\prime}\right\urcorner^{\prime},{ }^{\prime} \mathrm{O}^{\prime},{ }^{\prime} \boldsymbol{\prime}^{\prime}\right)$ & $0,1,1(<1$ st percentile $)$ \\
\hline \multicolumn{2}{|l|}{ Stroop Interference Test } \\
\hline Correct word reading (112) & 111 (>16th percentile) \\
\hline Correct color reading (112) & $26(<1$ st percentile $)$ \\
\hline
\end{tabular}

Figures in parentheses represent maximum scores.

dence and his occupations during that period, he incorrectly answered questions about personal experiences over the past 10 years, such as whether his son had finished his 18 months of service in the army and graduated from university. Although his son had already finished army duty 10 years before and graduated from university more than 5 years previously, the pa-
In order to investigate the semantic aspect of remote events, we administered the previously published Korean Public Event Recall Test that consists of 10 famous public events per decade from 1966 to 1997 in Korea [6]. When asked to answer questions with a single word or a short phrase, the patient showed correct responses only once in 30 questions. Subsequently, when forced to choose 1 of 4 choices, he replied correctly to 11 of 30 questions ( 3 in $1966-$ 1975, 4 in 1976-1985, 4 in 1986-1997). Fourteen age- and education-matched controls with no history of neurological and psychiatric illness were also tested. The average performance scores were 13.7 \pm 3.7 in free recall and $21.2 \pm 3.1(7.5 \pm$ 1.2 in $1966-1975,6.9 \pm 1.4$ in $1976-1985$, $6.9 \pm 1.6$ in 1986-1997) in the multiplechoice paradigm.

A gadolinium-enhanced MRI taken 15 days after symptom onset revealed a mass involving the hippocampal commissure, the body, and the anterior column of the bilateral fornices (fig. 1) [7]. An endoscopic biopsy performed 22 days after the onset proved the mass to be a diffuse, large $B$ cell lymphoma. Chemotherapy and radiotherapy were performed based on the result of the biopsy. A detailed neuropsychological test was not assessed again, but his son reported that the characteristics of the amnesia were unchanged 3 months after onset.

\section{Discussion}

Our patient differed from previously reported cases with localized fornix lesions [1-3], showing severe retrograde amnesia. As stated in the introduction, there has been 1 case report where the patient showed difficulty tagging the order of past events chronologically, while retaining the ability to recall the contents of past events [4]. Unlike these patients, ours failed to recall personal events of at least the past 10 years with a temporal gradient. This retrograde amnesia was not limited to the episodic component of events but also extended to the semantic aspect of events. That is, our patient had decreased knowledge of public events that had happened in the past 30 years and also decreased semantic knowledge of words as demonstrated in impaired naming on the Boston Naming Test.

The underlying mechanisms of retrograde amnesia associated with fornix lesion remain to be elucidated. In the previ- 

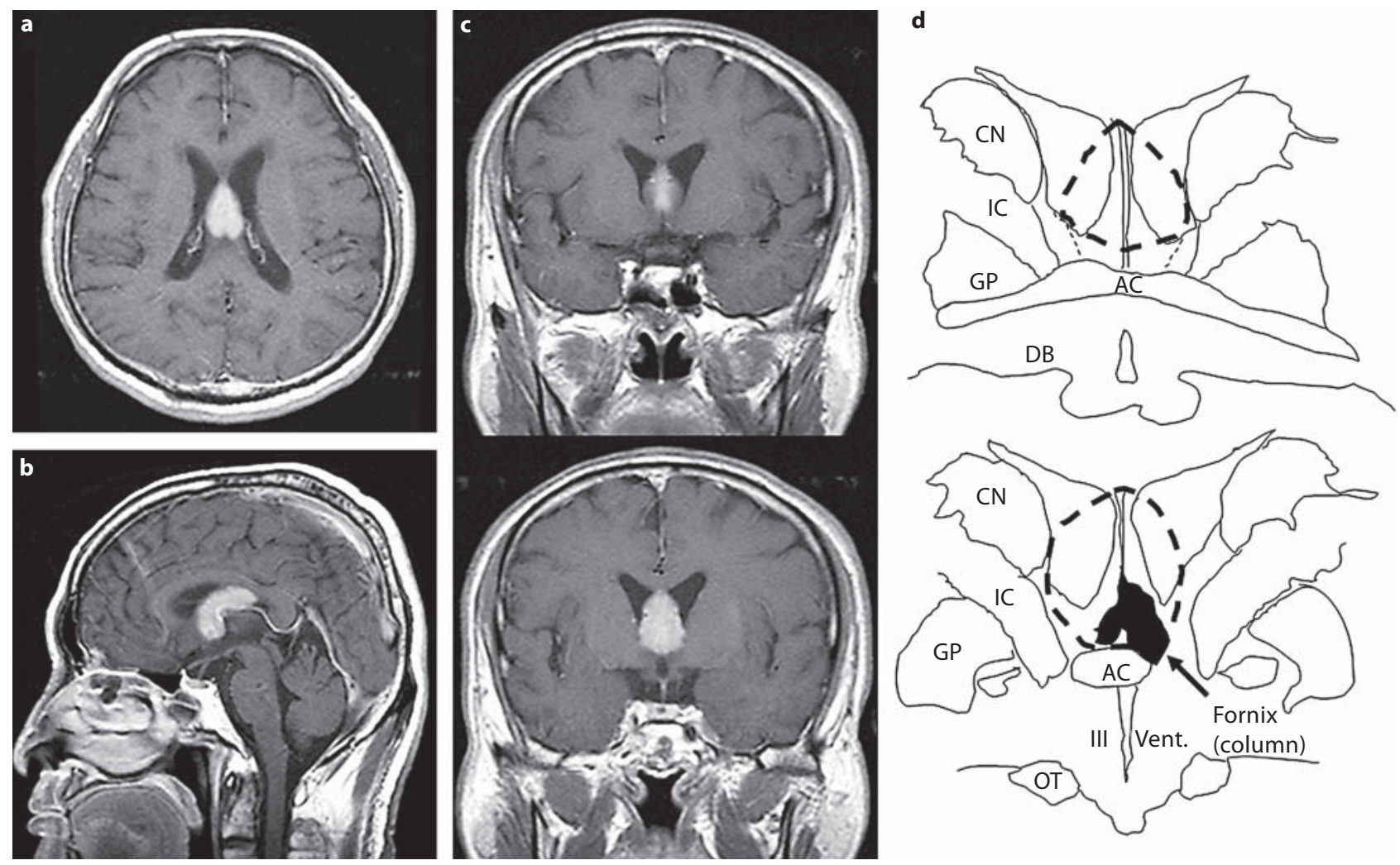

d Anatomical scheme of the lesion, corresponding to the MRI

Fig. 1. Gadolinium-enhanced MRI axial (a), sagittal (b) and coronal (c) images of the patient show that lymphoma invades the fornix selectively and completely along the long axis and the septum pallucidum only partly. The top of the coronal sections is at the anterior commissure and the lower is $6 \mathrm{~mm}$ caudal from the anterior commissure. The minor parts of the subcortical septal nuclei were involved, in addition to the fornix and the septum. coronal images, showing that the diagonal band is not invaded. Dashed line indicates the lesion. $\mathrm{AC}=$ Anterior commissure; $\mathrm{CN}$ = caudate nucleus; $\mathrm{DB}=$ diagonal band of Broca; $\mathrm{GP}=$ globus pallidus; $\mathrm{IC}=$ internal capsule; $\mathrm{OT}=$ optic tract; Vent. $=$ ventricle. ous report on temporal order retrograde memory deficit [4], the authors suggested that it was probably due to the disconnection between the frontal lobe and the hippocampus by disruption of the fornix. The fornix has dense connections with the medial region of the frontal lobe including the septal area and diagonal bands as well as anterior thalamus and mammillary body. Thus, the mechanism of retrograde amnesia associated with the fornix lesion might be attributable to the failure of the frontal lobe to retrieve the past memory stored in medial temporal areas because of the disconnection of the frontal lobe from the hippocampus [8]. Our observation that the patient was better at the recognition part than the free recall part of past public events may partly support this hypothesis. Alternatively, we cannot completely exclude the possibility that the lymphoma in our patient invaded structures adjacent to the fornix. Retrograde amnesia has been reported in patients with a lesion in the subcortical septal nuclei in the basal forebrain, such as the diagonal band of Broca and the nucleus accumbens $[9,10]$. However, we considered that these structures were not involved after mapping of the gadolinium-enhanced MRI of the lesion by superimposing on 2 schematic coronal sections from the neuroanatomical atlas [11].

One of the characteristics of our patient was frontal behavior such as apathy and indifference. Personality changes with a fornix lesion have been reported in only 1 case study in which the patient showed impulsiveness, aggressiveness, binge eating and hypersomnia [3]. The patient, however, had injuries not only to the fornix but also to the hypothalamus. It has been reported that lesions in frontal-basal areas of the brain, such as the septal nucleus, the accumbens nucleus, the innominated substance, and the anterior and medial thalamus, are associated with personality changes $[12,13]$. It is also well known that branches of the fornix send information to the septal area and the anterior and medial thalamus. Thus, we posit that apathy and indifference in our patient might be partly related to the disruption of the circuit connecting these structures. 
The extent of the fornix lesion in our patient was different from that of previous studies. The fornix consists of the crus, the commissure, the body, and the anterior columns [7]. Lesions of previous fornix cases were mainly confined to the anterior part of the fornix (anterior column or the body of the fornix) [1-4], whereas the lesion in our patient was more extensive, involving not only the anterior part as in previous cases (anterior column and the body) but the posterior part of the fornix (the commissure). It has been known that, as the fornix proceeds from the body to the anterior column, it sends out several branch fibers, terminating in different target sites such as the septal area, the anterior and lateral dorsal thalamic nuclei, the mammillary body, and the medial nucleus of the thalamus [7]. Thus, it may be almost impossible to completely disconnect the $\mathrm{Pa}$ pez circuit with a lesion at the level of the anterior columns. The injury to both anterior and posterior parts of the fornix in our patient may explain why he had severer amnesia involving both anterograde and retrograde events than previous cases.

\section{References}

1 Park SA, Hahn JH, Kim JI, Na DL, Huh K: Memory deficits after bilateral anterior fornix infarction. Neurology 2000;54:13791382.

2 Moudgil SS, Azzouz M, Al-Azzaz A, Haut M, Gutmann L: Amnesia due to fornix infarction. Stroke 2000;31:1418-1419.

- 3 Benabarre A, Ibanez J, Boget T, Obiols J, Martinez-Aran A, Vieta E: Neuropsychological and psychiatric complications in endoscopic third ventriculostomy: a clinical case report. J Neurol Neurosurg Psychiatry 2001; 71:268-271.

4 Yasuno F, Hirata M, Takimoto H, Taniguchi M, Nakagawa Y, Ikejiri Y, et al: Retrograde temporal order amnesia resulting from damage to the fornix. J Neurol Neurosurg Psychiatry 1999;67:102-105.

5 Kang Y, Na DL: Seoul Neuropsychological Screening Battery. Incheon, Human Brain Research \& Consulting Co, 2003.

6 Oh JY, Kwon JC, Chin J, Kim Ji, Lee JH, Choi $\mathrm{KG}$, et al: Retrograde amnesia following anterior thalamic infarction (in Korean). J Korean Neurol Assoc 2002;20:459-466.
7 Carpenter MB: Olfactory Pathways, Hippocampal Formation, and the Amygdala. Core Text of Neuroanatomy, ed 4. Baltimore, Williams \& Wilkins, 1991, pp 361-389.

8 Sagar HJ, Gabrieli J, Sullivan E, Corkin S: Recency and frequency discrimination in the amnesic patient H.M. Brain 1990;113:581602.

-9 Goldenberg G, Schuri U, Grömminger O, Arnold U: Basal forebrain amnesia: does the nucleus accumbens contribute to human memory? J Neurol Neurosurg Psychiatry 1999;67:163-168.

10 Hashimoto R, Tanaka Y, Nakano I: Amnesic confabulatory syndrome after focal basal forebrain damage. Neurology 2000;54:978980.

11 Haines DE: Neuroanatomy. An Atlas of Structures, Sections, and Systems, ed 4. Baltimore, Williams \& Wilkins, 1995.

12 Damasio AR, Graff-Radford NR, Eslinger PJ, et al: Amnesia following basal forebrain lesions. Arch Neurol 1985;42:263-271.

13 Perren F, Clarke S, Bogousslavsky J: The syndrome of combined polar and paramedian thalamic infarction. Arch Neurol 2005;62: 1212-1216. 